(26,47\%). Hipoplasia malar: 22 (64,71\%). Agenesias dentárias: 6 (17,65\%). Refluxo gastroesofágico: 6 (17,65\%). Afetação ATM: 15 (50\%), sendo artrose dor: $3(8,82 \%)$, artrose sem dor: $1(2,94 \%)$, dor sem artrose: 11 (32,35\%).

Conclusões: Este estudo retrospetivo permite-nos quantificar e caraterizar as manifestações orais de doentes com Stickler num estudo pioneiro em simultâneo com a realização de um censo da enfermidade na Espanha e em Portugal, alargando o estudo para os centros portugueses que tratan esta patología

http://doi.org/10.24873/j.rpemd.2017.12.167

\#147 Oncologia Oral: mucosite oral e o seu impacto no doente oncológico

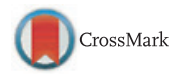

Jennifer Monteiro*, Augusta Silveira, Teresa Sequeira

Universidade Fernando Pessoa

Objetivos: Discutir os impactos da mucosite oral (MO) na sobrevivência e QdVRS em oncologia oral. Apresentar as normas recomendadas internacionalmente para actuar na MO.

Materiais e métodos: Revisão sistemática da literatura (2007-2017).

Resultados: A MO surge frequentemente associada à ulceração, sangramento e predisposição para infeção oral - os sinais e sintomas frequentemente se associam à má nutrição, internamento e interrupção no tratamento oncológico. A prevenção e o tratamento apoiam-se em recomendações/sugestões a favor e contra uma intervenção. O protocolo de cuidados orais, suplementos de zinco, crioterapia (30 minutos) e terapia com laser de baixa intensidade $(650 \mathrm{~nm})$ são sugeridos. No tratamento da dor, o uso de fentanil transdérmico, bochehos com soluções de morfina a 0,2\%, doxepina a 0,5\% ou benzidamina podem ser úteis. Os bochechos com soluções de sucralfato ou clorohexidina e a administração de pilocarpina não estão recomendados.

Conclusões: Uma adequada abordagem médica frente à MO tem como resultados um aumento da sobrevivência e uma optimização da QdVRS.

http://doi.org/10.24873/j.rpemd.2017.12.168

\#149 Relação entre o ângulo funcional mastigatório e o lado preferencial de mastigação

CrossMark

Iryna Fediv*, Ana Carvalho, Luís Silva, Patricia Fonseca

Instituto de Ciências da Saúde da Universidade Católica Portuguesa - Viseu, Centro de Investigação Interdisciplinar em Saúde da Universidade Católica Portuguesa

Objetivos: Os principais objetivos desta investigação são: 1- Identificar o ângulo funcional mastigatório; 2- Identificar o lado preferencial de mastigação; 3- Determinar a relação entre ambos.

Materiais e métodos: Foram avaliados 70 indivíduos (58,6\% mulheres; 41,4\% homens), 51 (72,9\%) da Clínica Universitária do Instituto de Ciências da Saúde da Universidade Católica Portuguesa e 19 (27,1\%) da Policlínica do Sátão. A medição do ângulo funcional mastigatório foi efetuada com um ortómetro, transferidor e régua milimétrica, registando-se a amplitude do ângulo formado na linha média pela interceção da trajetória seguida pelo incisivo central inferior no movimento de lateralidade em relação a um plano horizontal de referência, paralelo ao plano oclusal. Através do teste da pastilha elástica determinamos o lado preferencial de mastigação inicial e o lado de mastigação continuada (10 ciclos), registando-se como predominantemente unilateral direita, unilateral esquerda ou bilateral. Todos os procedimentos éticos e legais foram respeitados e os dados recolhidos foram introduzidos e analisados no software IBM SPSS Statistics ${ }^{\circledR}$ (versão 24) considerando um nível de significância de 5\% na inferência estatística.

Resultados: No que diz respeito ao ângulo funcional mastigatório, 47,1\% ( $\mathrm{n}=33)$ dos pacientes apresentam (à direita e à esquerda) ângulos iguais ou semelhantes; 34,3\% (n=24) têm o ângulo funcional mastigatório superior à esquerda e 18,6\% $(n=13)$ superior à direita. Dos 70 pacientes avaliados, 22,9\% $(\mathrm{n}=16)$ não apresentam um lado preferencial de mastigação, $28,6 \%(n=20)$ mastigam preferencialmente à esquerda e 48,6\% $(\mathrm{n}=34)$ mastigam preferencialmente à direita. Encontramos uma relação estatisticamente significativa entre o ângulo funcional mastigatório e o lado preferencial de mastigação ( $\mathrm{p}<=$ $0,05)$. Se o ângulo funcional mastigatório for diferente, a mastigação é preferencialmente unilateral para o lado de menor ângulo.

Conclusões: Uma vez que a maior parte dos pacientes não reconhece o seu lado preferencial de mastigação e que o mesmo tem repercussões funcionais importantes que podem afetar todos os componentes do sistema estomatognático (músculos, ossos, articulação, dentes e periodonto) e consequentemente comprometer uma reabilitação oral, clinicamente é importante que a existência de uma relação entre o ângulo funcional mastigatório e o lado preferencial de mastigação tenha sido provada.

http://doi.org/10.24873/j.rpemd.2017.12.169

\#150 Associação entre o Cronotipo e o Bruxismo Auto-Referido - Estudo entre Portugal e Brasil

Diana de Sousa*, Ricardo Dias, Maria João Rodrigues

Faculdade de Medicina da Universidade de Coimbra

Objetivos: Cada indivíduo tem um perfil e um relógio biológico de sono específico e individualizado definido como cronotipo. O bruxismo é definido como uma parafunção da musculatura mastigatória, que culmina no apertar e ranger de dentes e/ou na contratura da musculatura sem os dentes estarem necessáriamente em contacto. Tem uma etiologia multifatorial, mediada centralmente e onde intervêem e interagem fatores fisiopatológicos, morfológicos e psicossociais. Entre os fatores fisiopatológicos incluem-se as perturbações do sono. O conhecimento e a modificação do cronotipo pode mediar e contribuir para um prognóstico mais favorável no controlo e prevenção de determinadas patologias. Deste modo, o objetivo principal deste trabalho é verificar a possível relação entre bruxismo auto-referido e cronotipo. 
Materiais e métodos: Como resposta à necessidade, revelada pela literatura, de estudos para verificar a possível relação entre cronotipo e bruxismo, foi desenvolvido um estudo multicêntrico entre Portugal e Brasil. O trabalho aqui apresentado é um estudo piloto, envolvendo uma amostra de 70 alunos de medicina dentária do primeiro e último anos do curso, procurando estabelecer a relação entre: possível bruxismo de sono auto-referido, bruxismo de vigília e o cronotipo. Para isso recorreu-se a um inquérito de auto-resposta desenvolvido especificamente para o estudo, e complementado com a obtenção do valor MEQ (Morningness-eveningness Questionnaire) através da resposta por cada participante ao questionário online.

Resultados: Foi feita a análise estatística com a variável dependente Bruxismo de Vigília e com as restantes variáveis. O mesmo não foi realizado para o Bruxismo do Sono devido a baixo número de alunos que o relataram, o que impossibilitou essa análise. Sendo um estudo piloto, os resultados obtidos apontam para uma potencial relação entre o cronotipo e bruxismo. Esta relação revelou-se particularmente significativa para os alunos classificados como definitivamente vespertinos quanto ao cronotipo.

Conclusões: O conhecimento individual do cronotipo permitirá a adopção de medidas comportamentais que permitam melhorar a qualidade de vida, rendimento pessoal e académico, qualidade do sono e, ainda, controlar o comportamento bruxómano e consequentemente, minimizar as consequências e sequelas a nível dos dentes, músculos e articulações. Um estudo numa amostra ampliada torna-se imperativo, não só numa população específica como a agora estudada, mas também para a população geral.

http://doi.org/10.24873/j.rpemd.2017.12.170

\#151 Poderá o ambiente familiar e escolar predizer os hábitos de uma criança?

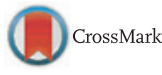

Maria Beatriz Vilaça*, Carolina Soares, Mariana Seabra, Andreia Figueiredo

Universidade Católica Portuguesa

Objetivos: Perceber qual a relação entre o ambiente em que a criança está habitualmente inserida durante o dia e os seus hábitos alimentares, bem como com os seus hábitos de sucção nutritivos e não nutritivos.

Materiais e métodos: Foi realizado um estudo epidemiológico descritivo e transversal, com recurso a uma amostra de conveniência, tendo-se obtido o maior número possível de crianças dos 0 aos 6 anos, que frequentavam a consulta de saúde infantil da USF Rio Dão, Santa Comba Dão - Viseu, entre Outubro de 2016 e Fevereiro de 2017. Foi aplicado um questionário ao responsável de cada criança, o qual incluía dados do inquirido e da criança. Foi entregue a cada tutor uma declaração de consentimento informado. O estudo foi aprovado pela Comissão de Ética da instituição proponente e pela instituição pública onde os dados foram recolhidos. Para o processamento e análise dos dados, recorreu-se ao programa Statistical Package for the Social Sciences ${ }^{\circledR}$. De forma a ser possivel verificar a existência de relações significativas entre duas variáveis qualitativas, foi aplicado o teste Qui Quadrado ou a correção de continuidade. Em todos os testes, utilizou-se um nível de significância de $5 \%$.

Resultados: A amostra foi constituída por 111 crianças, sendo que $73,9 \%$ ( $n=82$ ) ficavam na creche/escola e $26,1 \%$ permaneciam em casa. Das 29 crianças que ficavam em casa, a maioria, 79,3\% ( $\mathrm{n}=23)$ estava ao cuidado dos pais. A maioria das crianças que estavam integradas na creche/escola $(65,9 \%)$ frequentava a mesma entre há 2 e 4 anos. Apenas 11,0\% frequentava a escola há 5 ou mais anos. O local onde a criança permanece durante o dia apresentou-se significativamente relacionado com o facto da criança mamar $(p=0,000)$, comer com talheres $(\mathrm{P}=0,000)$ e com a forma como bebe os líquidos que não o leite $(p=0,034)$. O modo de acolhimento da criança também apresentou uma relação significativa $(p=0,013)$ com o facto da criança já ter usado chupeta.

Conclusões: A maioria das crianças que mamava estava em casa e não usava chupeta nem nunca usou, enquanto a esmagadora maioria que estava na creche usava/usou chupeta, sugerindo a relação entre o uso da chupeta e variáveis de natureza psicoemocional inerentes à adaptação da criança a um meio desconhecido. A maior parte das crianças que estava na creche comia com talheres e utilizava apenas o copo/caneca para beber os líquidos que não o leite, o que parece sinalizar uma maior tendência para a autonomização em contexto escolar por oposição ao ambiente familiar.

http://doi.org/10.24873/j.rpemd.2017.12.171

\section{\#152 Biodisponibilidade salivar de fluoretos pós escovagem dentária em crianças: estudo piloto}

Isabel Vilela*, Joana Leonor Pereira, Ana Daniela Soares, Teresa Xavier, Ana Messias, Ana Luísa Costa

Faculdade de Medicina da Universidade de Coimbra

Objetivos: A biodisponibilidade salivar de fluoretos é influenciada por comportamentos individuais, como a frequência e duração da escovagem, a quantidade de dentífrico utilizado e o regime de bochecho pós escovagem. O presente estudo piloto objetivou determinar se existe influência na biodisponibilidade salivar de fluoretos no decurso de diferentes comportamentos pós escovagem dentária com um dentífrico convencional em crianças.

Materiais e métodos: $O$ estudo compreendeu uma amostra aleatória, constituída por crianças de 7 a 9 anos $(n=3)$, sem lesões de cárie e patologias sistémicas relevantes, com valores de fluxo salivar estimulado dentro dos parâmetros considerados normais. Salvaguardados os requisitos éticos estabeleceram-se dois protocolos pós escovagem dentária padronizada: (1) apenas cuspir o excesso de dentífrico e (2) o bochecho com $5 \mathrm{~mL}$ de água destilada. A colheita de saliva estimulada, para ambos os regimes, foi realizada antes da escovagem dentária ('baseline'), imediatamente a seguir e em intervalos de 5, 30 e 60 minutos após a escovagem dentária. Depois de recolhidas todas as amostras $(n=30)$, preservaram-se a -80oC para posterior determinação da concentração de flúor recorrendo ao potenciómetro GLP 22 (Crison ${ }^{\circledR}$, Barcelona, Spain) acoplado a um elétrodo de ião seletivo de flúor DC219-F (Mettler Toledo $\left.{ }^{\circledR}, \mathrm{OH}, \mathrm{USA}\right)$. 